\title{
ASPECTOS E FATORES DA PRODUTIVIDADE EM PESQUISA, DESENVOLVIMENTO E INOVAÇÃO
}

\author{
Kurt Politzer \\ Indústrias Químicas Taubaté S/A, Rua Irmãos Albernaz 300, 12050-190 Taubaté - SP
}

\begin{abstract}
ASPECTS AND FACTORS FOR PRODUCTIVITY IN R\&D\&I. Comparison of national budgets for R\&D is often made but it should consider the relative productivity and their factors. In Brazil, inefficiency factors as well as their causes have been diagnosed since the late 60's and solutions have been proposed within various governmental organisms, from CNPq to the strategy think tanks. Problems that hinder R\&D and innovation in Brazil are reviewed from a historical perspective together with the proposed solutions providing a detailed analysis of the difficulties that have to be overcome to achieve a more effective innovation environment, adequate for the present times, challenges and opportunities.
\end{abstract}

Keywords: R\&D productivity; innovation environment; difficulties for R\&D and innovation.

Os países efetuam comparações de gastos em atividades de pesquisa, desenvolvimento e inovação, mas são raras as manifestações explícitas sobre a produtividade relativa destas atividades e os fatores que as influenciam.

No Brasil, os problemas, bem como suas causas são, em geral, conhecidos, bem estudados e as respectivas soluções apontadas em detalhe. Considere-se, por ex., a questão do atraso tecnológico nos processos produtivos da indústria brasileira, bem como nos processos de pesquisa em instituições de ensino e pesquisa do Brasil, em conformidade com o objetivo da Comissão Parlamentar Mista de Inquérito criada em 1991, destinada a investigar as causas e as dimensões do referido atraso. O parecer, bem como as recomendações de medidas, constantes da publicação do Relatório Final, publicado em 1992, de autoria da relatora, então deputada Irma Passoni, constituem um elenco das constatações e recomendações que demonstram a profundidade das análises e soluções apontadas.

Infelizmente, apenas uma diminuta parte foi objeto de real efetivação, decorridos doze anos da publicação citada ${ }^{1}$.

Outro exemplo, na mesma linha de raciocínio, diz respeito ao reconhecimento da importância da pesquisa industrial como fator de desenvolvimento, revelada claramente no relatório de grupo de trabalho, designado pelo Conselho Nacional de Pesquisas em 1967, cujas conclusões e recomendações constam de publicação do Conselho Nacional de Pesquisas em $1968^{2}$.

$\mathrm{O}$ projeto relativo a incentivos fiscais, neste momento a ponto de ser enviado ao Congresso, e que complementa a recente Lei de Inovação, finalmente efetivará o assunto, decorridos 37 anos da publicação em apreço.

Há uma constatação feita há anos, relativa às dificuldades de transformação de esforços de pesquisa acadêmica em inovação industrial, tendo havido iniciativas, tanto do lado de universidades, quanto de indústrias, de criação de mecanismos para aproximação de academia e indústria, tais como entidades criadas por várias universidades e o Instituto Euvaldo Lodi criado pela Confederação Nacional da Indústria em 1969, após palestras realizadas no Instituto Roberto Simonsen em $1967^{3}$.

As principais etapas da evolução da ciência, tecnologia e inovação no Brasil têm sido objeto de análises em várias apresentações ${ }^{4}$, como exemplificado a seguir:

*e-mail: diretoria@iqt.com.br

\section{EVOLUÇÃO DO ESFORÇO GOVERNAMENTAL EM C E T}

Apoio à formação de cientistas; apoio a instalações para pesquisa e, apoio à parceria empresa/instituição universitária e de pesquisa.

\section{COOPERAÇÃO CIENTÍFICA E TECNOLÓGICA NACIONAL E INTERNACIONAL}

Compra de tecnologia; compra de tecnologia com presença acionária do fornecedor de tecnologia; transferência de tecnologia com real absorção da mesma e base para novos progressos tecnológicos; P e D na empresa; parcerias científicas e tecnológicas em âmbito nacional e, parcerias científicas e tecnológicas em âmbito internacional.

\section{INTERAÇÃO INSTITUIÇÕES DE PESQUISA/INDÚSTRIA}

Uso de Instituições de pesquisa pela indústria para tarefas analíticas e para adequação de equipamentos de processos e operações unitárias; iniciativas de pesquisa por instituições de ensino e pesquisa com vistas à eventual utilização industrial e, cooperação entre instituições de ensino e pesquisa e indústria na escolha e desenvolvimento de temáticas de interesse conjunto.

A análise de dificuldades a superar na cooperação empresaUniversidade/Instituição de Pesquisa também é tema importante ${ }^{4}$.

Estudos detalhados de vários autores estão reunidos em publicações da ABICT e patrocínio do Instituto Euvaldo Lodi5 ${ }^{5}$.

Merece destaque a iniciativa da Associação dos Diplomados da Escola Superior de Guerra - ADESG - sobre Integração Universidade Indústria ${ }^{6}$ com 12 conferencistas, bem como sobre Ciência e Tecnologia - 1984 com 58 participantes $^{7}$ e 1985 com 26 expositores $^{8}$.

Só a recente Lei de Inovação, ao estabelecer o papel de unidades de inovação, contribuiu para permitir uma solução à problemática em causa.

Uma pesquisa, empreendida pela ABIQUIM em 1996 entre as empresas associadas, revelou alguns aspectos negativos criados pela abertura intempestiva do mercado brasileiro no setor da indústria química, conforme o texto transcrito a seguir, o qual explica, em parte, o atraso tecnológico do setor.

"A ABIQUIM procedeu a uma pesquisa de situação e opinião sobre aspectos tecnológicos entre as empresas associadas.

A análise dos dados e informações resultantes, aliada ao conhecimento da ABIQUIM no trato dos problemas da indústria quí- 
mica brasileira, leva a preocupações resumidamente expostas no Quadro 1.

\section{DESENVOLVIMENTO DA MODERNA INDÚSTRIA QUÍMICA}

A moderna química teve sua instalação dificultada e postergada em função das incertezas de suprimento das matérias-primas importadas em vista dos freqüentes períodos de dificuldades no balanço de pagamentos.

A situação começou a se modificar na década de 1950, com o início da instalação de refinarias de petróleo no país, com possibilidades de geração de algumas matérias-primas básicas. Na década de 60 , surgiu um impasse quanto à instalação de Indústria Petroquímica (que forneceria os principais insumos da Indústria Química Moderna), quanto à inclusão no monopólio da Petrobrás. A solução foi encontrada através da criação da Petroquisa e do avanço tecnológico que permitiu a desvinculação da Indústria Petroquímica do uso de sub-produtos de refinarias, mediante o uso de nafta e, em menor escala, gás natural.

O surgimento da Indústria Petroquímica, principalmente na década de 70, acentuou e ampliou o desenvolvimento de atividades de engenharia e da indústria de bens de capital diversificados no país, o que havia sido incentivado pelas instalações das refinarias pela Petrobrás, modificando o quadro tecnológico, o qual, até então, era dependente, fundamentalmente, do setor açucareiro.

Na década de 80, desenvolveu-se a Indústria Química, utilizadora de insumos disponíveis, de produções de maior valor agregado e acentuada complexidade tecnológica, mas que, de um modo geral, não teve tempo de se consolidar adequadamente, através de atividades inovadoras oriundas de esforços endógenos de pesquisa e desenvolvimento de processos e produtos.

\section{A DÉCADA ATUAL}

A abertura econômica abrupta, expôs o mercado interno e removeu proteções sem a simultânea adoção de medidas tendentes a adaptar as externalidades às condições competitivas globalizadas, trouxe dificuldades principalmente às indústrias mais verticalizadas.

Vários sub-setores da Indústria Química instalada no Brasil viram minguar as contribuições marginais das suas atividades produtivas, comprimidas entre os efeitos de uma inflação interna de custos, que embora controlada, subsistiu teimosamente, e a barreira de preços representada pelos limites oriundos dos preços internacionais à taxa cambial praticamente constante.

As empresas, pressionadas pela crise e pela rapidez do processo de mudanças, recorreram a reestruturações organizacionais, eliminando postos de trabalho e, no processo, sacrificando as atividades de coleta de informações, planejamento, pesquisa e desenvolvimento, a fim de sobreviverem dentro das condições criadas. Não foi possível preservar o patrimônio humano das empresas, nem, em geral, planejar aumentos de produtividade através de modernizações exigentes de investimentos, em função do alto custo de capital e da redução da geração própria de lucros. E aquelas que o fizeram enfrentam grandes dificuldades em fazerem face aos juros e amortizações dos empréstimos contratados.

Desta forma, persistindo as condições delineadas e só agora sendo tomadas algumas medidas tendentes a reduzir o "Custo Brasil", não há perspectivas de, a curto prazo, serem tomadas as atividades de inovação, embora reconhecidamente essenciais à sobrevivência competitiva a médio e longo prazos. Daí gera-se a conclusão óbvia de que a única possibilidade de redução do hiato tecnológico, exacerbado pelas circunstâncias referidas, reside na mobilização do setor onde se concentram os recursos humanos criativos, ou seja, as Universidades e os Institutos de Pesquisa Governamentais. Para este fim, e visando viabilizar a transferência, em tempo útil, de inovações da Academia para o setor produtivo, torna-se necessária a desburocratização dos procedimentos de aporte de recursos com a conseqüente agilização deste, eliminando-se os longos períodos de contratação e adotando-se organizações de projetos baseados em estruturas matriciais, com ampla liberdade, dentro de programações adotadas, de ação dos coordenadores de projetos e de interação dos mesmos com o setor produtivo. Cumpre acentuar que a mera utilização de conhecimentos não apropriáveis e, portanto, livremente dis-

Quadro 1. Análise de dificuldades a superar

\begin{tabular}{ll}
\hline ITEM & UNIVERSIDADE/INST. PESQUISA \\
\hline 1. Cultura & Reação ao envolvimento externo na determinação \\
& de bases estratégicas e aspectos operacionais; \\
& ceticismo, recusa de autoridade; escolha sem \\
& interferência de temas de pesquisa; preocupação \\
& de evitar tornar-se caudatário de empresa; \\
& preocupação limitada com cronograma físico e \\
& com aplicação de resultados da pesquisa
\end{tabular}

2. Aspectos Legais

3. Diferenças conceituais pesquisadores
Burocracia complexa quanto a aquisições de equipamentos e produtos; dificuldades de elaboração de acordos de confidencialidade, de convênios sobre divisão de trabalhos e propriedade de resultados/patentes

Conceito de tecnologia atribuído a resultados de trabalhos em etapa laboratorial

Apesar de dificuldades econômicas as universidades conseguiram, de modo geral, manter e melhorar o nível de seus quadros

\section{EMPRESA}

Respeito ao esquema organizacional com aspectos participativos; preocupação com cronograma físico e financeiro; condição de retorno de investimentos

Simplicidade e rapidez decisórias nas empresas de porte médio e pequeno; preocupação com confidencialidade, sigilo, propriedade de tecnologia como ativo

Conceito de tecnologia sendo utilizável após ensaios adequadamente avaliados em etapas piloto e estudos de mercado e retorno de investimento

O impacto da abertura obrigou empresas a reduzir custos fixos, prejudicando quadros de $\mathrm{C}, \mathrm{T}$ e I 
poníveis, se esgota rapidamente se não houver uma contribuição contínua inovadora, supridora destes conhecimentos.

$\mathrm{O}$ contexto em que se desenrola a competitividade em escala global necessita do aprofundamento do conhecimento científico como uma das forças propulsoras, da aplicação das inovações tecnológicas dentro da preocupação da preservação ambiental e das condições dignas de vida e trabalho. Estes aspectos constituem balisamentos essenciais das atividades de pesquisa e desenvolvimento no mundo atual, adquirindo importância crescente na orientação das tendências de inovação, que não podem ser orientadas exclusivamente pelas forças de mercado."

O lançamento, em novembro de 2003, das "Diretrizes de Política Industrial, Tecnológica e de Comércio Exterior" e a organização de Fóruns de Competitividade relativos a vários assuntos e setores prioritários são eventos de importância para o desenvolvimento econômico e social do país. Neste contexto, a apresentação de Salerno ${ }^{9}$ ressalta os principais aspectos decorrentes dos eventos citados.

$\mathrm{O}$ enfoque de produtividade em pesquisa, desenvolvimento e inovação e a interdependência destas atividades passaram a constituir aspectos prioritários para o sucesso da política em causa. São também preocupações internacionais conforme, mais uma vez, confirmado na conferência da IUPAC "Inovação na Indústria Química: o caminho de química pura à química aplicada"10.

Os conceitos relativos à inovação, no que concerne ao seu impacto e relacionamento com pesquisa básica e desenvolvimento, têm sofrido modificações na abrangência e processualística, substituindo-se o conceito da evolução linear desde as idéias iniciais, passando pela pesquisa básica, desenvolvimento e finalmente inovação; pelo reconhecimento da amplitude da influência da inovação sobre aspectos sociais, produtos internos brutos, financeiros, científicos, tecnologias de informação, recursos humanos e organizacionais, instrumentais, etc. e adotados conceitos ternários, com reciclagens entre ciência e tecnologia, bem como sistemas organizacionais tipo ad hoc adaptados às pecularidades dos assuntos em pauta.

Acrescem, como variáveis exógenas, influências tipo globalização, barreiras alfandegárias e técnicas, influências ambientais, sustentabilidade, etc. Aparecem técnicas combinatórias e de experimentação de alto rendimento como aceleradoras e redutoras de $\operatorname{custos}^{11}$.

Neste ambiente, os governos preocupam-se com barreiras à inovação que atrasam e encarecem o processo inovatório, sendo responsabilizadas as barreiras regulatórias, não pelos objetivos vi- sados, mas pela demora e complexidade dos seus procedimentos, muitas vezes oriundas das abrangências excessivas dos conhecimentos necessários às decisões.

Assim, os E.U.A. recentemente estabeleceram a "Iniciativa de Inovação Nacional" pelo "Conselho de Competitividade". A UE preocupa-se com o avanço dos E.U.A.. No caso brasileiro, é extensa a rede de controles para produtos químicos, envolvendo os Ministérios da Ciência e Tecnologia, Defesa, Justiça, Agricultura, Saúde e do Meio Ambiente ${ }^{12}$.

Falta, no caso brasileiro, a criação de uma rede de contatos dos integrantes dos órgãos administradores dos aspectos regulatórios com pessoas conhecedoras dos assuntos em causa.

Tem-se observado haver uma melhoria de qualidade e de rapidez de atendimento dos órgãos licenciadores com a aproximação ao nível local, o que já era uma constatação obtida nas medidas adotadas pelo então Ministério da Desburocratização ${ }^{13}$.

Quanto a este aspecto, cumpre observar algumas das conclusões de da Silva ${ }^{14}$ : "O Estado tem um papel vital a desempenhar na incorporação do processo inovatório. A qualidade da sua burocracia é determinante".

\section{REFERÊNCIAS}

1. Congresso Nacional - CPMI; Causas e Dimensões do Atraso Tecnológico - Relatório Final, Brasília, 1992.

2. Presidência da República - Conselho Nacional de Pesquisas; "A pesquisa Industrial no Brasil como Fator de Desenvolvimento", Rio de Janeiro, 1968.

3. Chiaverini, V.; Pesquisa Tecnológica na Universidade e na Indústria Brasileiras, Livraria Pioneira: São Paulo, 1968.

4. Politzer, K.; Inovação - Alguns Aspectos Condicionantes do Cenário Brasileiro, ABIQUIM: SP, 2002, p. 10 e 17.

5. IEL - ADESG; Interação Universidade Empresa, Brasília 1998-1999.

6. IEL - ADESG; Integração Universidade-Indústria Hoje, APEL Ed. S/A: Rio de Janeiro, 1971.

7. IEL - ADESG; Ciência e Tecnologia: Um desafio Permanente, Rio de Janeiro, 1984

8. IEL - ADESG; Programa Nacional de Estudos sobre Ciência e Tecnologia, Rio de Janeiro, 1985.

9. Salerno, M. S.; Parcerias Estratégicas 2004, nº. 19, 13.

10. Kopytowski, J. A.; Chemistry International 2004, September - October, 3.

11. Spitz, P. H.; The Chemical Industry at the Millennium, Maturity, Restructuring, and Globalization, Chemical Meritage Press: Philadelphia, 2003, p. 82 e 83.

12. Mourão, H. N. M.; "Produtos Químicos Controlados", I Seminário Nacional sobre Controle de Bens Sensíveis, 2005.

13. Beltrão, H.; Descentralização e Liberdade, Ed. UnB, $3^{\text {a }}$ ed., 2002, p. 21, $30,31,33,34,49$ e 50 .

14. Gonçalves da Silva, C.; Debate Nacional, INEP, 1994. 